\title{
Cross-Cultural Factors That Influence Adjustment Process of International Students in Malaysian Public Universities
}

\author{
Chong Poh Yee $e^{1}$ and Bibi Noraini Mohd Yusuf $f^{2}$ \\ School of Business Innovation and Technopreneurship \\ Universiti Malaysia Perlis
}

\begin{abstract}
International students' enrolment in higher education in Malaysia has expanded widely in scope, volume, and complexity, giving rise to a myriad of challenges and difficulties in their adjustment process, which have to be understood and addressed. In this study, the cross-cultural factors that influence psychological, sociocultural, and self-realization adjustments amongst international students studying in Malaysian public universities were examined. The purpose of this research was to gauge a better understanding of the difficulties and challenges encountered by them when pursuing higher education opportunities in Malaysian public universities, and how they had managed to overcome the necessary adjustments. A research survey based on 31-item questionnaires was formulated. Stratified random sampling methodology was adopted in the distribution of 250 questionnaires, with a total of 218 responses received. Data were coded and analyzed using the Statistical Package for Social Sciences' software. The variables, socio-cultural adjustment, and self-realization adjustment showed negative correlations towards their adjustment process. The outcomes should enable university faculties and staff to recognize foreign students' needs, and effectively offer supportive campus resources and services to assist them in their adjustment process.
\end{abstract}

Keywords: International students, Adjustment process, Psychological adjustment, Socio-cultural adjustment, Self-realization adjustment

\section{INTRODUCTION}

International higher education in Malaysia is progressing rapidly, where umpteen higher education reforms have been introduced to promote international entrants. In its Higher Education Blueprint (2015-2025), the country aims to attract 250,000 international students, with a vision to become a major global education hub by 2035 . International students have now become an integral component of the Malaysian higher education system.

Figure 1.1: International Students Enrolment in Malaysia (2016-2017).

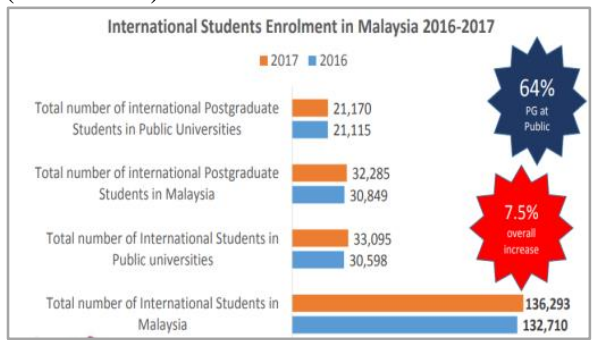

Source: Nordin (2018) [1]. Recent Development of International Higher Education in Malaysia.
Figure 1.2: International Students in Malaysia: Top 10 Sending Countries 2017

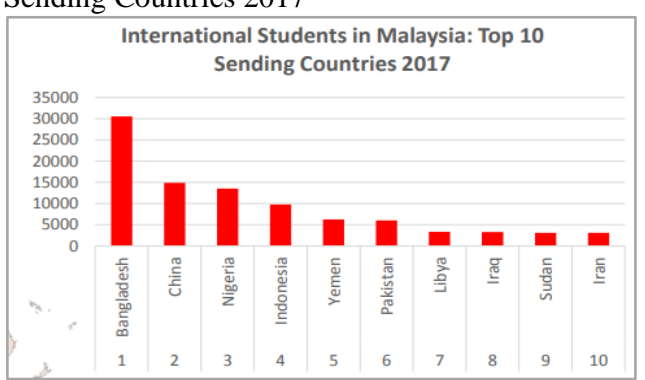

Source:

https://www.statista.com/statistics/866731/internationalstudents-in-malaysia-by-country-of-origin/

A 2017 research studies by Asia-Pacific Association for International Education show overall increase of $7.5 \%$ to 33,095 in the total number of international students in Malaysian public universities, (undergraduates and postgraduates of 11,925 and 21,170 respectively) [2]. The bulk of the enrolment was from Bangladesh, China, Nigeria, Indonesia, etc [2].

Six (6) factors caused expatriates to feel stressful when working abroad, which are: communication, cultural differences in the workplace, daily life, 
relationships with family and colleagues, financial problems and lastly, social inequality [3]. After overcoming homesickness and loneliness for the second time, they would have realized that they had actually adapted to their new life as an international student unnoticed. International students in Malaysia enjoyed equal learning opportunities with local students, with access to local language, gender roles, religious conservatism, and temporary accommodation. International students must strive to gain access to information about the host country's geographic region, educational system, and cultural context [4]. Any culturally heterogeneous group of international students have a tendency to experience umpteen challenges in their educational ventures [5]. For instance, American students in foreign countries had encountered difficulties such as language differences, education and economic issues, housing, inability to become socially accepted, and racial prejudice [6].

With their growing influx in Malaysia, greater studies have been directed towards understanding and accommodating to their adjustment process, including addressing psychological, socio-cultural, and self-realization adjustment [7]. Nevertheless, researchers have not examined the correlations between cross-cultural factors that influence the above three types of the adjustment process, which this study aims to achieve. Previous studies have explored adjustment on one or a limited number of variables, but this study has sought to investigate a range of variables that seemed to influence their adjustment process, and ultimately increasing public understanding of the issues.

The specific objectives are 1) To determine how the factors of life conditions will affect the psychological adjustment among international students in Malaysian public universities; 2) To examine the impacts of adjustment of own culture to host country's culture, affinity relations and adaptation to socio-cultural adjustment of foreign students in Malaysian public universities, and 3) To study the relationship between students' adjustment factors in Malaysian public universities.

Owing to a dearth of current research information or data on the factors impacting international students' adjustment process, this research seeks to explore in more details on the cross-cultural factors that lead to adjustment process for international students in Malaysian public universities.

\section{LITERATURE REVIEWS}

Difficulties are encountered by any international students when integrating into any local university environment, and several study themes on the psychological adjustment, such as Berry's acculturation framework [8] or social identity theory from $\mathrm{ABC}$ [9], yielded various results, all showing positive correlations between psychological adjustment and academic achievement of international students [10]. There is a positive correlation between impacts of adjustment of own culture to host country's culture to socio-cultural adjustment of international students [11] and a significant relationship between the levels of acculturative stress and overall socio-cultural adaptation of international students. These results implied that, as acculturative stress levels decreases, foreign students' socio-cultural adaptation level to the university's environment increases and viceversa [12]. In examining the cross-cultural factors that affect adjustments of foreign care workers in Japan the researchers classified the cross-cultural adjustment of care professionals into three categories, namely psychological, socio-cultural, and self-realization [13]. Cross-cultural adjustment themes have been investigated in terms of: psychology-related variables, such as increased psychological health; socio-cultural-related variables, such as learning skill or knowledge in the host culture and motivation to learn host language [14]; self-concept variables, such as sense of meaningful life [13]; academic achievement, and behavioural variables, particularly the acquisition of culturally appropriate skills. Their investigations showed that there are basically two cross-cultural domains, namely psychological and socio-cultural for international students. Adjustment refers to the response to the demands and pressures of social environment imposed by the individual [15]. Hence, the factors that influence psychological, sociocultural, and self-realization adjustments of international students in Malaysian public universities were examined throughout this research study.

\section{Psychological Adjustment}

Psychology describes the consciousness, behavior and social interaction. Mental health status and other factors (biological, environmental) are predictors of international students' psychological adjustment. Mental health refers to cognitive, behavioral and emotional well-being, and also includes the ability of one to enjoy life - a balance between living activities and efforts to achieve psychological resilience [16]. Psychological adaptation in this study refers to psychological well-being and life satisfaction. Well-being and life satisfaction are some of the concepts that represent different levels of specificity in studying positive adaptation [17]. Support services to international students' adjustment encourage them to maintain a multicultural openness, reducing cultural conflicts and minimizing academic difficulties [18]. The psychological adjustment of international students is 
related to the emotional aspects of adapting to the new cultural environment, including evaluations of anxiety, depression, self-esteem, and life satisfaction [19]. Studies have demonstrated the psychological distress and the state of cultural shock, where they felt lost and confused when experiencing unfamiliar lifestyles, are significantly and negatively correlated with both psychological and socio-cultural adaptation of newcomers [20]. Another research found out that Afghan students in University Kebangsaan Malaysia (UKM) felt depressed as it was their first time being away from home in pursuing higher education in a foreign country [21].

\section{Socio-Cultural Adjustment}

Socio-cultural adjustment refers to the acquisition of skills that are appropriate in the host culture and be able to master the general abilities of daily life in a new cultural context, in overcoming learning shocks[19]. It also consists of adaptation to social living condition, adaptability with host-country's nationals, acquisition of specific cultural knowledge skills, and the ability to fit into the host's culture by interacting with their peers [22]. It is a combination of social and cultural elements, and their adjustments are often seen as the level of comfort and familiarity of the individual. It can be broadly divided into two categories; internal factors (personal characteristics) and external factors (degree of differences in the new living environment) [23] and these factors include customs, lifestyles and values, all considered as social characteristics. Social factors include family, reference groups, role, and status in society, while cultural aspects include language, religion, belief, material culture, education, technology, and attitudes. Learning shocks refers to the difficult emotions and experiences faced in adapting to a new learning environment [24]. Inability to speak the host country's language can make them excessively be dependent on their colleagues or make them feel isolated [25]. Understandably, local students would have own groupings and rarely talk to people outside their groups and thus not being interactive with the international students. Canadian Bureau for International Education [26] suggested that local students lack interest in making international friends. Lack of interest and enthusiasm can often lead to in-differences and isolation.

\section{Self-Realization Adjustment}

Self-realization means developing an individual's readiness and harmonious development of different aspects of human beings, and applying enough efforts to expand personal potential. Scientists have emphasized the importance of student motivation, implying that students' learning direction forms professional self-realization and determines their performance intensity in the educational environment [27]. The importance of collaborative coercion in cultivating their self-realization is a way to overcome inner hesitation and personal problems. Once the self-realization stage I reached, new vision and understanding of oneself would be sustained with permanent happiness, better relationships with others, and freedom from fears and anxieties. Establishing a strong relationship with their peers (Americans) is the most important factor that affects personal adjustment of international students [28]. Developing strong social network with local students can provide them with the solid foundation and motivation to explore an unfamiliar cultural environment. Self-determinant theory is a broad motivational framework that is centred on the beliefs that all humans have basic innate psychological needs of autonomy, relatedness, and competency, and that social environment plays an important role in the actualization of these needs [29]. In recent years, research on SDT in the field of education has shown that higher levels of self-determination can lead to positive educational outcomes (more indepth participation, better conceptual learning and higher persistence).

\section{METHODOLOGY}

Quantitative data collection methodology was used in the questionnaire technique, using a list and a rating scale, with the sample size determined by using Krejcie and Morgan [30] table.

$\mathrm{H}_{1}$ : There is a relationship between the factors of life conditions with the psychological adjustment among the international students in Malaysian public universities.

$\mathrm{H}_{2}$ : There is a relationship between the impacts of adjustment of own culture to host culture, affinity relations and study place adaptation with sociocultural adjustment of international students in Malaysian public universities.

$\mathrm{H}_{3}$ : There is a relationship between the adjustment factors among the international students in Malaysian public universities.

Results

Overall, an $87.2 \%$ response rate was received from the respondents, summarized below.

\begin{tabular}{|l|c|}
\hline Number of Questionnaires Distributed & 250 \\
\hline Number of Questionnaires Collected Back & 218 \\
\hline Response Rate & $87.2 \%$ \\
\hline $\begin{array}{l}\text { Number of Questionnaires Used for } \\
\text { Analysis }\end{array}$ & 218 \\
\hline
\end{tabular}

Table 4.1: Sample Profile

Table 4.2: Demographic Profile of Respondents $(n=218)$ 


\begin{tabular}{|c|c|c|c|}
\hline $\begin{array}{l}\text { Primary } \\
\text { Category }\end{array}$ & Sub-Category & Frequency & Percent \\
\hline \multirow[t]{2}{*}{ Gender } & Male & 145 & 66.5 \\
\hline & Female & 73 & 33.5 \\
\hline \multirow{4}{*}{$\begin{array}{l}\text { Level of } \\
\text { Study }\end{array}$} & Diploma & 0 & 0 \\
\hline & Degree & 142 & 65.1 \\
\hline & Master & 45 & 20.6 \\
\hline & Ph.D. & 31 & 14.2 \\
\hline Duration in & $\begin{array}{l}\text { Less than } 1 \\
\text { year }\end{array}$ & 46 & 21.1 \\
\hline \multirow[t]{3}{*}{ Malaysia } & $2-3$ years & 85 & 39.0 \\
\hline & 4-5 years & 53 & 24.3 \\
\hline & $\begin{array}{l}\text { More than } 5 \\
\text { years }\end{array}$ & 34 & 15.6 \\
\hline \multirow{2}{*}{$\begin{array}{l}\text { Marital } \\
\text { Status }\end{array}$} & Single & 182 & 83.5 \\
\hline & Married & 36 & 16.5 \\
\hline \multirow{25}{*}{$\begin{array}{l}\text { Country of } \\
\text { Origin }\end{array}$} & Africa & 32 & 14.7 \\
\hline & China & 26 & 11.9 \\
\hline & Yemen & 26 & 11.9 \\
\hline & Indonesia & 15 & 6.9 \\
\hline & Myanmar & 13 & 6.0 \\
\hline & Jordan & 13 & 6.0 \\
\hline & Nigeria & 11 & 5.0 \\
\hline & Bangladesh & 8 & 3.7 \\
\hline & Pakistan & 7 & 3.2 \\
\hline & Afghanistan & 7 & 3.2 \\
\hline & Somalia & 7 & 3.2 \\
\hline & Vietnam & 7 & 3.2 \\
\hline & France & 6 & 2.8 \\
\hline & Korea & 5 & 2.3 \\
\hline & Iran & 5 & 2.3 \\
\hline & Philippines & 4 & 1.8 \\
\hline & Iraq & 4 & 1.8 \\
\hline & Finland & 4 & 1.8 \\
\hline & Morocco & 3 & 1.4 \\
\hline & Libya & 3 & 1.4 \\
\hline & Sri Lanka & 3 & 1.4 \\
\hline & India & 3 & 1.4 \\
\hline & Fiji & 2 & 0.9 \\
\hline & $U K$ & 2 & 0.9 \\
\hline & Sudan & 2 & 0.9 \\
\hline
\end{tabular}

Out of the 218 respondents, a total of $145(66.5 \%)$ and $73(33.5 \%)$ respondents were males and females respectively. In terms of level of study, none enrolled for Diploma courses and for higher tertiary levels, $65.1 \%, 20.6 \%$, and $14.2 \%$ were first-time degrees, Masters, and $\mathrm{Ph} . \mathrm{D}$ categories respectively. A total of 46 respondents had stayed in Malaysia for less than 1 year, 85 for 2-3 years, 53 for 4-5 years and lastly 34 for more than 5 years. Majority of the respondents $(83.5 \%)$ were singles. On the country of domiciles, Africa accounted for $14.7 \%$, followed by
China and Yemen (11.9\%), Indonesia (6.9\%) and $6.0 \%$ from Myanmar and Jordan, with small numbers from The United Kingdom, Fiji, Sudan, Morocco, and Sri Lanka.

\section{Reliability Analysis}

The survey questionnaires comprised five parts: demographic profiles, adjustment process, psychological adjustment, socio-cultural adjustment, and self-realization adjustment. On the dependent and independent variables (DV and IV respectively), the answer options were given in afive scales rating, from "Highly Disagree", "Disagree", "Neutral", "Agree" and to "Highly Agree". The reliability analysis for each dependent variable and independent variables were computed with results in Table 4.3, showing that the dependent variable - adjustment process, has a poor Cronbach's alpha value with only 0.339 (lower than 0.6), indicating that the dependent variable is less reliable. However, two of the independent variables: psychological and self-realization adjustment have shown an acceptable Cronbach's values, of 0.681 and 0.670 respectively, signifying being moderately reliable. Socio-cultural adjustment has the highest Cronbach's value (0.794), and thus it is more closely to reach high reliability.

Table 4.3: Reliability Statistics

\begin{tabular}{lcc}
\hline Variables & $\begin{array}{c}\text { N of } \\
\text { items }\end{array}$ & $\begin{array}{c}\text { Cronbach's } \\
\text { Alpha }\end{array}$ \\
\hline $\begin{array}{l}\text { Adjustment Process } \\
\text { Psychological }\end{array}$ & 5 & 0.339 \\
$\begin{array}{l}\text { Adjustment } \\
\begin{array}{l}\text { Socio-cultural } \\
\text { Adjustment }\end{array}\end{array}$ & 7 & 0.681 \\
$\begin{array}{l}\text { Self-Realization } \\
\text { Adjustment }\end{array}$ & 8 & 0.794 \\
\hline
\end{tabular}

\subsection{Descriptive Analysis}

The descriptive statistics of the responses were computed and shown in Table 4.5, depicting both the mean and standard deviation values for each DV and all the IVs. The Self-Realization adjustment (an IV) has the highest mean and lowest standard deviation, illustrating that most of the positive responses came from questions of this section, whereas the SocioCultural adjustment (an IV), had the second-highest mean value and second-lowest standard deviation, followed by the Adjustment Process (DV) and lastly, the Psychological Adjustment (an IV). This indicates that the least positive responses came from questions in this section.

\begin{tabular}{lcc}
\hline Variables & Mean & Std. Deviation \\
\hline Adjustment Process & 3.3688 & 0.59533 \\
Psychological & 3.1107 & 0.65112
\end{tabular}

Adjustment 
Poh Yee \& Bibi Noraini / International Journal of Business and Management, 4(2) 2020, Pages: 30-38

$\begin{array}{lcc}\text { Socio-Cultural } & 3.8131 & 0.60685 \\ \text { Adjustment } & & \\ \text { Self-Realization } & 4.1254 & 0.55573\end{array}$

Adjustment

Table 4.5: Descriptive Statistics

A total of 122 respondents $(56 \%)$ and 96 respondents (44\%) had perceived the Adjustment process to be at "High" and "Moderate" levels respectively. On Psychological adjustment, the perceptions were $60.1 \%, 36.2 \%$, and $3.7 \%$ at the "High", "Moderate" and "Low" levels respectively. 169 respondents $(77.6 \%)$ felt that there was a "High" level of Socio-Cultural adjustment followed by 49 $(22.4 \%)$ at "Moderate" level. Majority of the respondents were conscious of the "High" level of Self-Realization adjustment (91.7\%).

Table 4.6: Level of Dependent Variable and Independent Variable

\begin{tabular}{|c|c|c|c|c|}
\hline Variables & & Level & Frequency & Percent \\
\hline \multirow{3}{*}{$\begin{array}{l}\text { Adjustment } \\
\text { Process }\end{array}$} & $0-1.67$ & Low & 0 & 0 \\
\hline & $\begin{array}{l}1.68- \\
3.35\end{array}$ & Moderate & 96 & 44.0 \\
\hline & $\begin{array}{l}3.36- \\
5.00\end{array}$ & High & 122 & 56.0 \\
\hline \multirow{3}{*}{$\begin{array}{l}\text { Psychological } \\
\text { Adjustment }\end{array}$} & $0-1.67$ & Low & 8 & 3.7 \\
\hline & $\begin{array}{l}1.68- \\
3.35\end{array}$ & Moderate & 131 & 60.1 \\
\hline & $\begin{array}{l}3.36- \\
5.00\end{array}$ & High & 79 & 36.2 \\
\hline \multirow{3}{*}{$\begin{array}{l}\text { Socio-cultural } \\
\text { Adjustment }\end{array}$} & $0-1.67$ & Low & 0 & 0 \\
\hline & $\begin{array}{l}1.68- \\
3.35\end{array}$ & Moderate & 49 & 22.5 \\
\hline & $\begin{array}{l}3.36- \\
5.00\end{array}$ & High & 169 & 77.5 \\
\hline \multirow{3}{*}{$\begin{array}{l}\text { Self-Realization } \\
\text { Adjustment }\end{array}$} & $0-1.67$ & Low & 1 & 0.5 \\
\hline & $\begin{array}{l}1.68- \\
3.35\end{array}$ & Moderate & 17 & 7.8 \\
\hline & $\begin{array}{l}3.36- \\
5.00\end{array}$ & High & 200 & 91.7 \\
\hline
\end{tabular}

**. Correlation is significant at the 0.01 level (2-tailed).

*. Correlation is significant at the 0.05 level (2-tailed).

Research has established a linear relationship and association between cross-cultural factors that influenced the adjustment process of these respondents at $95 \%$ and $99 \%$ confidence levels respectively (Strong relationships between any variables exist at $95 \%$ and at $99 \%$ levels of confidence).

\begin{tabular}{|l|c|c|c|c|}
\hline & $\begin{array}{c}\text { Adjustment } \\
\text { Process }\end{array}$ & $\begin{array}{c}\text { Psychological } \\
\text { Adjustment }\end{array}$ & $\begin{array}{c}\text { Socio- } \\
\text { cultural } \\
\text { Adjust } \\
\text { ment }\end{array}$ & $\begin{array}{c}\text { Self- } \\
\text { Realization } \\
\text { Adjustment }\end{array}$ \\
\hline $\begin{array}{l}\text { Adjustment } \\
\text { Process }\end{array}$ & 1.000 & $0.341^{* *}$ & $-0.171^{*}$ & -0.010 \\
\hline $\begin{array}{l}\text { Psychological } \\
\text { Adjustment }\end{array}$ & $0.341^{* *}$ & 1.000 & -0.130 & 0.127 \\
\hline $\begin{array}{l}\text { Socio-cultural } \\
\text { Adjustment }\end{array}$ & $-0.171^{*}$ & -0.130 & 1.000 & $0.556^{* *}$ \\
\hline $\begin{array}{l}\text { Self- } \\
\text { Realization } \\
\text { Adjustment }\end{array}$ & -0.010 & 0.127 & $0.556^{* *}$ & 1.000 \\
\hline
\end{tabular}

Table 4.7: Correlations

Regression Analysis

Table 4.8 showed that the standardized beta for psychological adjustment, socio-cultural adjustment, and self-realization adjustment were at $0.318,-0.146$ and 0.030 respectively, indicating that psychological adjustment has the strongest effect towards the adjustment process. Significant value (p-value) was applied to determine whether the null hypothesis was accepted or not. A p-value of less than 0.01 means acceptance of the null hypothesis and at more than 0.05 means otherwise. Here, only the p-value for psychological adjustment was less than 0.01 (at 0.00 ).

\begin{tabular}{cl}
\hline r-values & Strengths of Relationship \\
\hline 0.00 until 0.29 & Negligible correlation \\
0.30 until 0.49 & Low correlation \\
0.50 until 0.69 & Moderate correlation \\
0.70 until0.89 & High correlation \\
0.90 until 1.00 & Very High correlation \\
\hline
\end{tabular}

Table 4.8: Pearson Correlation Coefficient

However, the other two independent variables: socio-cultural adjustment and self-realization adjustment showed p-values of more than 0.05. Hence, the null hypothesis for psychological adjustment variable was accepted, whereas the null hypothesis for both the socio-cultural adjustment and self-realization adjustment variables were not supported and rejected.

The Durbin Watson statistic is a number (from 0 to 4) that tests for autocorrelation in the residuals from a statistical regression analysis, where values approaching 0 indicate positive autocorrelation and values toward 4 indicate negative autocorrelation. A value of 2 means no autocorrelation in the sample. In this research, the value was 1.847 (almost equal to 2), thus safe to conclude that there were no autocorrelation in the samples.

\section{SUMMARY}

Results of the hypothesis tested are described in Table 4.9. 


\begin{tabular}{|c|l|c|}
\hline Hypothesis & \multicolumn{1}{|c|}{ Statement of Hypothesis } & Results \\
\hline $\mathrm{H}_{1}$ & $\begin{array}{l}\text { There is a relationship between the factors of life conditions such as living } \\
\text { environment, accommodation and infrastructure, and a person's psychological health } \\
\text { such as degree of nervousness, depression, stress and homesickness with the } \\
\text { psychological adjustment among the international students in Malaysian public } \\
\text { universities. }\end{array}$ & $\begin{array}{c}\text { Accepted } \\
\text { culture, affinity relations and study place adaptation with socio-cultural adjustment } \\
\text { of international students in Malaysian public universities. }\end{array}$ \\
\hline $\mathrm{H}_{2}$ & $\begin{array}{l}\text { There is a relationship between the adjustment factors such as personal goals and } \\
\text { meaningful life with self-realization adjustment among the international students in } \\
\text { Malaysian public universities. }\end{array}$ & Rejected \\
\hline $\mathrm{H}_{3}$
\end{tabular}

Table 4.9: Results of Hypothesis Testing

From the 3 hypotheses examined, the first hypothesis $\left(\mathrm{H}_{1}\right)$ was accepted and the remaining 2 hypotheses $\left(\mathrm{H}_{2}\right.$ and $\left.\mathrm{H}_{3}\right)$ were rejected. Life conditions and a person's psychological health influenced their psychological adjustment, whereas the other two factors:- 1) impacts of adjustment of own culture to host culture, affinity relations and study place adaptation had no influence on their socio-cultural adjustment, and 2) the adjustment factors and meaningful life had no influence on the self-realization adjustment.

\section{DISCUSSION AND CONCLUSION}

The findings revealed that psychological adjustment process was more prominently noted among the respondents compared to the other two adjustment process. Psychological adjustment factors $\left(\mathrm{H}_{1}\right)$ indicated positive correlation but both socio-cultural and self-realization adjustment factors $\left(\mathrm{H}_{2}\right.$ and $\mathrm{H}_{3}$ respectively) had shown negative correlation towards the adjustment process.

It was positively tested in $\mathrm{H}_{1}$ that overseas students had encountered difficulties to adapt with local life. This outcome is consistent with the previous study by Alghamdi \& Otte [31], asserting the challenges and toughness for the overseas students to change and adapt in a new country. Luna and Hassan [32] discovered that African students in Malaysia were able to cope with the cross-cultural challenges. In acknowledging the large cultural disparities between foreign and host countries, they would need to undergo the psychological adjustment process in order to cope with adjustment. Failure to cope would have negative consequential ramifications. The findings also implied that the higher level of adaptation was primarily due to higher the level of psychological adjustment. On the level of a person's psychological health, the higher the level of coping with their personal emotions, the higher would be the level of psychological adjustment process. These two findings have been proven by Wang et al. [33].

Outcome of the second hypothesis $\left(\mathrm{H}_{2}\right)$ contradicted the research by (Abdullah, Adebayo and Talib, [34], the latter stating that there is a significant relationship between socio-cultural factors among the international students with their socio-cultural adjustment. This situation had resulted in depression and uncertainties in the new study place. Thus their presence in Malaysian public universities would not have significant problems of adjustment to host culture. This is inconsistent with the findings by Taylor \& Ali [35], in concluding that most international students face difficulties in adjusting to socio-cultural environment of the host country. The negative correlation relationship between sociocultural factors and socio-cultural adjustments were attributed to isolation issues, making it difficult for the former to join into the latter's social life events and no initiatives were taken to communicate.

The third findings $\left(\mathrm{H}_{3}\right)$ was inconsistent with the research by Hatanaka and Tanaka [35], who had stated that social interactions between the international students with the Japanese colleagues had increased their motivation for self-advancement in studies. The extracurricular sessions availed on inter-relations with the Japanese had improved the life satisfaction of the respondents that led to the development of goals for their future or academic life. There is a dearth of researches conducted on examining the relationship between these adjustment factors (personal goals and meaningful life) with self-realization adjustment, thus this present study can be considered as a breakthrough or a new discovery. Anne [36] stated that international students who learned foreign languages to achieve specific goals were instrumentally motivated and those lacking in cultural curiosity or even prejudice against the target culture are likely to struggle with 
learning foreign languages, resulting in a lower level or no self-realization adjustment.

\section{Implications of the Findings}

This study imparts the public's awareness and having a better understanding of the difficulties and challenges encountered by future respondents. It highlights the factual reasons on psychological, socio-cultural, and self-realization adjustment factors among them, and how they managed to make the necessary adaptation in the adjustment process. Going forward, continuous improvements can be made by the government and universities to address the acculturation and adaption challenges of aspiring respondents.

\section{Recommendations}

In order to overcome language proficiencies, foreign students should be provided with adequate training in Malay or English and they are encouraged to apply for internships in local companies or participating in local charity activities. These would enable them to learn about the new culture of the host country. In adapting to a new socio-cultural environment, they will experience acculturative stress, thus cross-cultural training is warranted as guidance to succeed in their academic learning and overcome psychological stress. Universities can create environmentally and culturally sensitive adjustment programs by roping in the seniors and ex-foreign students to share their experience on the adjustment process.

\section{Limitations of Research}

Time was the main limitation owing to shorter period on data collection process, mode of questionnaires' (250) distribution, geographical coverage and involving varied nationalities. The second limitation was lack of cooperation as not many were willing to participate and lastly, the study scope involved only Malaysian public (no private) universities. These limitations had given rise to insufficiency in the number of respondents participating (218). Future research should address all these and should also consider other variables such as academic adjustment and/or environment adjustment. Comparative analysis should target respondents from other sectors, such as care workers, teachers or lecturers, doctors, and engineers.

\section{Conclusion}

The results indicated a significant positive relationship between the factors of life conditions and a person's psychological health against the psychological adjustment of the respondents. Two important findings were that there were no significant correlations between 1) the impacts of adjustment of own culture to host culture, affinity relations and study place adaptation with that of socio-cultural adjustment, and 2) the adjustment factors with self-realization adjustment. Several study limitations highlighted should be addressed in future research, such as time constraints, limited variations in the nationality of the respondents, lack of accurateness, respondents from the private universities and targeting them from other sectors as well. The study outcomes have enabled better awareness and understanding of the difficulties and challenges experienced by them when seeking higher education opportunities in Malaysia, and how they managed to acculturate into the new living environment. From this perspective, it can be concluded that psychological adjustment factor was more prominently noted as compared to the sociocultural adjustment and self-realization factors.

\section{REFERENCES}

[1] Nordin, Y. (2018). Recent Development of International Higher Education in Malaysia. Retrieved from: https://www.apaie2018.org/sites/default/files/Sp eaker\%20Slides/Recent\%20Development $\% 20$ o f\%20International $\% 20$ Higher $\% 20$ Education $\% 2$ 0in\%20Malaysia.pdf.

[2] Global Survey. (2017). Number of international students studying in Malaysia in 2017: Retrieved on:

https://www.statista.com/statistics/866731/inter national-students-in-malaysia-by-country-oforigin/

[3] Doki, Sasahara, S., Sinichiro \& Matsuzaki, Ichiyo. (2018). Stress of working abroad: a systematic review. International Archives of Occupational and Environmental Health. 91. 118. 10.1007/s00420-018-1333-4.

[4] Raihan, M.G. \& Sandaran, S.C. (2017). Sociocultural Adaptation Challenges of International Students at a Higher Learning Institution in Malaysia. LSP International Journal. 4(2), 2017, pp. 5-101.

[5] Ali, A.A. \& Omer, H.A.M. (2015). Cognitive Adjustment of International Students in a Malaysian Public University. International Journal for Innovation Education and Research. 3, No-12.

[6] Wu, H., Garza, E., \& Guzman, N. (2015). International student's challenge and adjustment to college. Education Research International. Article ID 202753, 9 pages.

[7] Mustaffa, C.S. \& Ilias, M. (2013). Relationship between Students Adjustment Factors and Cross Cultural Adjustment: A Survey at the Northern University of Malaysia. Intercultural Communication Studies. XXII: 1 (2013).

[8] Arash, E (2018). Acculturation and Migration: Interview with Dr. J. W. Berry. Retrieved from: https://www.psychologytoday.com/us/blog/find 
ing-new-home/201803/acculturation-and-

migration-interview-dr-j-w-berry.

[9] Islam, G. (2014). Social Identity Theory. (Tajfel, Turner). Encyclopedia of Critical Psychology. Publisher: Springer-Verlag. Editors: T. Teo. Retrieved from:

https://www.researchgate.net/publication/28120 8338_Social_Identity_Theory.

[10] Khalid, M. \& Muhammad, M. I. (2015). Psychological Adjustment and Academic Achievement among Adolescents. Journal of Education and Practice. ISSN 2222-288X (Online) 6(1), 2015.

[11] Maricel C. San Diego (2017). Sociocultural Adjustment of Foreign Students in the Philippines, $1(1)$. https://doi.org/10.22662/IJEMR.2017.1.1.049.

[12] Hajara Mahmood \& Monica Galloway Burke (2018). Analysis of Acculturative Stress and Socio-cultural Adaptation Among International Students at a Non-Metropolitan University. Journal of International Students. 8(1) p 2843072018.

[13] Hatanaka, K \& Tanaka, T (2016). Crosscultural Factors That Influence Adjustments of Foreign Care Workers in Japan: Towards a Three-Layered Structural Model. Regular Issue. 2 (3) , pp. 01-17.

[14] Umer, S., Othman, Z. \& Hassan, K. (2016) Socio-Cultural Obstacles to Women's Participation in Politics, In Rural Areas of Balochistan, Pakistan. International Journal of Business and Social Science. 7(10), Pp 145-153.

[15] Sharma, J. (2016). Adjustment: Process, Acheivement, Characteristics, Measurement And Dimensions. International Journal of Academic Research. ISSN: 2348-7666; 3-1(2), pp. $42-45$.

[16] Goel, S., Narang, D.K. \& Koradia, K. (2013). Marital Adjustment, Mental Health and Frustration Reactions during Middle Age. International Journal of Scientific and Research Publications. 3(9), pp. 1-8. ISSN 2250-3153.

[17] Gökçe Bulgan \& Ayşe Çiftçi (2017). Psychological Adaptation, Marital Satisfaction, and Academic Self-Efficacy of International Students. Journal of International Students.7(3), 687-702. DOI: 10.5281/zenodo.570028.

[18]. Hengyu, Q. (2016). A Study of the International Students' Motivation to Study Chinese. International Journal of Language and Linguistics. 4(4), Pages: 147-152.

[19] Simon, O. (2015). Predictors of international students' psychological and sociocultural adjustment to the context of reception while studying at Aarhus University, Denmark. Scandinavian Journal of Psychology. 56(6), Pp. 717 - 725. https://doi.org/10.1111/sjop.12258.

[20] Presbitero, A. (2016). Culture shock and reverse culture shock: The moderating role of cultural intelligence in international students' adaptation. International Journal of Intercultural Relations. 53, 28-38. doi: 10.1016/j.ijintrel.2016.05.004.

[21] Ahmad, A.L, Azimi, H., Salleh, S., Mohamad, E.M.W. \& Sannusi, S.N. (2015). The Intercultural Adaptation Experience of Afghan Students in Malaysia. SHS Web of Conferences 33, $00056 \quad$ (2017). DOI: $10.1051 /$ shsconf/20173300056.

[22] Wu, H., Garza, E. \& Guzman, N. (2015). International Student's Challenge and Adjustment to College. Education Research International. Article ID 202753, 9 pages, 2015. https://doi.org/10.1155/2015/202753.

[23] Mesidor, J.K. (2016). Factors that Contribute to the Adjustment of International Students. Journal of International Students. 6(1) (2016), pp. 262-282.

[24] Narouz, L.I.I. (2018). Challenges and Culture Shock Symptoms among International Nursing Students at Cairo University. IOSR Journal of Nursing and Health Science (IOSR-JNHS). 7(4) Ver. V (Jul.-Aug. 2018), PP 58-66.

[25] Anita Vulić-Prtorić \& Neele Oetjen (2017). Adaptation and Acculturation of International Students in Croatia. Collegium antropologicum, 41 (4), 2017. Retrieved from: https://hrcak.srce.hr/205231.

[26] Canadian Bureau for International Education. (2015). The Integration Challenge: Connecting International Students with their Canadian peers. Retrieved from:

https://cbie.ca/wpcontent/uploads/2016/04/CBIE-Research-inBrief-2-The-Integration-Challenge-EN.pdf.

[27] Natalya B. Pugacheva, Sergey G. Ezhov, Igor V. Kozhanov, Marina B. Kozhanova, Svetlana V. Ogorodnikova, Alexey G. Oshaev, Andrey I. Timonin, Galina S. Goloshumova. (2016). The Model of Self-realization Readiness Formation of Research Universities Students in the Process of Civic Education. International Review of Management and Marketing. 2016, 6(1), 128133.

[28] Glass, C. R. (2014). International student adjustment to college: Social networks, acculturation, and leisure. Journal of Park and Recreation Administration, 32(1), 7-25.

[29] Lehnen, T.L. (2015). Psychology Theoretical Approaches and Application in Practice.docx. Psychology Theoretical Approaches and Application in Practice. Retrieved from: https://www.academia.edu/35548059/Psycholo gy_Theoretical_Approaches_and_Application_i n_Practice.docx

[30] Krejcie, R.V., \& Morgan, D.W., (1970). Determining Sample Size for Research Activities. Educational and Psychological Measurement. 
[31] Alghamdi, H. \& Otte, S. (2016). The Challenges and Benefits of Study Abroad. International Journal of Humanities and Social Science. 6(5), pp. 16-22.

[32] Luna Madanga \& Zubair Hassan (2014). Determinants of Cross Cultural Adjustments, Perceived Academic Performance and Intention to Leave Among African Students in Malaysia. International Journal of Accounting and Business Management (Online), Volume 2, Issue 2.

[33] Wang, K.T, Wei, M., Zhoa, R., Chuang, C. \& Li, F. (2015). The cross-cultural loss: Development and psychometric evaluation. Psychological Assessment, 27(1), 42-53.

[34] Abdullah, Maria Chong; Adebayo, Areo Sunday; Talib, Abd Rahim. Relationship between Demographic Factors, Social Support and Sociocultural Adjustment among International Post Graduate Students in a Malaysian Public University. Journal of Educational and Social Research. 5(2), p. 87, pp. 87-92. ISSN 2240-0524.

[35] Taylor, G. \& Ali, N. (2016). Learning and Living Overseas: Exploring Factors that Influence Meaningful Learning and Assimilation: How International Students Adjust to Studying in the UK from a Socio-Cultural Perspective. Educ. Sci. 2017, 7, 35; doi:10.3390/educsci7010035.

[36] Anne Merritt (2013). What motivates us to learn foreign languages? Retrieved from https://www.telegraph.co.uk/education/educatio nopinion/9900074/What-motivates-us-to-learnforeign-languages.html. 